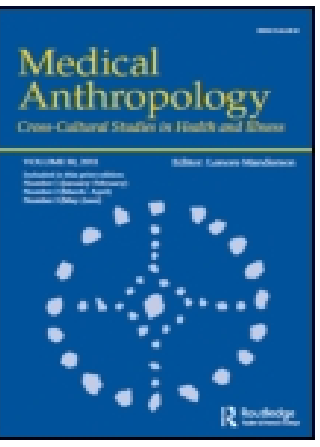

Medical Anthropology

Cross-Cultural Studies in Health and IIIness

ISSN: 0145-9740 (Print) 1545-5882 (Online) Journal homepage: http://www.tandfonline.com/loi/gmea20

\title{
Breaking Silences and Upholding Confidences: Responding to HIV in the Lihir Islands, Papua New Guinea
}

\section{Susan R. Hemer}

To cite this article: Susan R. Hemer (2015) Breaking Silences and Upholding Confidences:

Responding to HIV in the Lihir Islands, Papua New Guinea, Medical Anthropology, 34:2, 124-138, DOI: $10.1080 / 01459740.2014 .944263$

To link to this article: https://doi.org/10.1080/01459740.2014.944263

曲 Published online: 16 Sep 2014.

Submit your article to this journal ๘

Џll Article views: 211

Q View related articles $\square$

View Crossmark data ¿

Citing articles: 1 View citing articles 


\title{
Breaking Silences and Upholding Confidences: Responding to HIV in the Lihir Islands, Papua New Guinea
}

\author{
Susan R. Hemer \\ Anthropology \& Development Studies, University of Adelaide, Australia
}

\begin{abstract}
Various forms of silence are understood to characterize the response to HIV/AIDS in the Lihir Islands in Papua New Guinea. While some efforts have been made to prevent HIV and educate residents, these seem not to have been in proportion to its classification as a high-risk setting for transmission, given social factors associated with the Lihir gold mine. Confidentiality is both practiced yet critiqued in Lihir as another form of silencing that detracts from efforts to emphasize the serious nature of HIV, promote its prevention, and care for those who live with it. 'Breaking the silence' has come to be seen as key to preventing HIV in Lihir, yet while certain silences are acknowledged, others have escaped scrutiny.
\end{abstract}

Keywords confidentiality, health promotion and prevention, HIV/AIDS, Papua New Guinea, secrecy

Silence itself - the things one declines to say, or is forbidden to name, the discretion that is required between different speakers-is less the absolute limit of discourse . . . than an element that functions alongside the things said, with them and in relation to them within over-all strategies. There is no binary division to be made between what one says and what one does not say; we must try to determine the different ways of not saying such things, how those who can and those who cannot speak of them are distributed, which type of discourse is authorized, or which form of discretion is required. ... There is not one but many silences. (Foucault 1990:27)

Silence and secrecy in the literature on HIV are often negative, associated with stigma and discrimination, and constructed as an obstacle to the prevention and treatment of HIV. In contrast, 'breaking the silence,' and frank and open discussions about sexuality, have come to be seen as core elements in HIV prevention (Hardon and Posel 2012; Nguyen 2005, 2013). Silence is used to refer to the lack of knowledge or understanding about HIV, and a lack of prevention efforts against HIV (e.g., Beadle-Holder 2011; Kimani-Murange et al. 2013). For people with

SUSAN R. HEMER is a social anthropologist based at the University of Adelaide in Australia, whose work focuses on medical and psychological well-being and development, particularly in Papua New Guinea. Her book Tracing the Melanesian Person: Emotions and Relations in Lihir (2013) explores what it means to be Lihirian in a world that has rapidly changed in the last century through the work of Christian missions, government administration, and the development of the Lihir gold mine.

Address correspondence to Susan Hemer, Discipline of Anthropology \& Development Studies, University of Adelaide, SA 5005 Australia. E-mail: susan.hemer@adelaide.edu.au 
HIV, secrecy has been linked to isolation or the strain of upholding a secret (Fielden, Chapman, and Cadell 2011; Smith and Neidermyer 2009). Cultural silences around taboo subjects such as sex can lead to difficulties in HIV prevention (Bond 2010). Silence or secrecy is also often discussed in reference to the reluctance to get tested or to disclose test results to partners, family, and friends (Obermeyer and Osborn 2007). On the other hand, sometimes silence enables providers to create safe or confidential spaces (e.g., Fielden et al. 2011).

Anthropologists and other researchers have critically examined these understandings of the virtues of breaking the silence, noting that this can assume that fact and knowledge can overcome cultural beliefs (Davis and Manderson 2014; Lepani 2012; Manderson 2014; Pigg 2005). Rather than taking them for granted, Burchardt (2013) examines silences around sexuality as discursive constructions. Butt has raised concerns that "adhering to global AIDS talk" (2008:132) and "neutral biomedical language" can silence other concerns (2008:119). Other researchers have nuanced different ways of knowing yet not saying (Bond 2010; Moyer 2012), or getting around the "socially unspeakable" though joking or tangential references (McPherson 2008:235).

In contrast to silence, confidentiality has become a core value in testing and treating HIV and AIDS. As Angotti states, "global HIV testing policy became anchored in a human rights framework, one that encourages testing by guarding against HIV-related stigma and discrimination" (2012:366). This global approach has rested in recent years on the '3Cs' of HIV testing: counseling, informed consent, and confidentiality. Confidentiality refers to the "practice of keeping secret all facets of the relationship between client and health care worker" (Butt 2011:320). In general this refers to limiting access to patient records and test results, and not disclosing patient information without their consent (Hardon et al. 2012). In some countries this is tempered by legislation that requires HIV-positive individuals to disclose their status to sexual partners (for example, Kenya and Burkina Faso; Hardon et al. 2012). This legislation is part of an ongoing debate about balancing the right to confidentiality with the need to prevent transmission to others (Obermeyer et al. 2013).

Papua New Guinea has followed the global lead in making confidentiality a key aspect in HIV testing and treatment. In 2003 the Parliament passed the HIV/AIDS Management Prevention Act (HAMP Act), which clearly specifies the legal provisions for voluntary counseling and testing, and the importance of confidentiality. In this context, confidentiality refers to the practice of taking "all reasonable steps to prevent disclosure" of a person seeking, refusing, or having a HIV test; actually having, or being presumed to have, HIV; or being related to someone who has or may have HIV (Government of PNG 2003:13). It is unlawful to divulge test results to anyone other than the person tested without consent (other than minors), except where the infected person has been counseled, has refused to change their behavior or notify their partner, and there is a real risk of transmission (Ibid:14).

The benefits of confidentiality are largely assumed, although some literature discusses the breaches of confidentiality or difficulties of maintaining it in practice (see for example, Obermeyer, Baijal, and Pegurri 2011; Obermeyer et al. 2013). Butt argues that confidentiality "does not resonate with cultural values, particularly those around nurturing and care of sick family members" in Papua (2011:320), and that it is often impossible to maintain confidentiality in village settings due to the mobile population and the visibility of health workers (330). Angotti, in the context of rural Malawi, contends that confidentiality is seen as "contributing to the spread of AIDS in their communities" (2012:372). Hence confidentiality can be seen in certain contexts as a complex virtue that is both desirable and unattainable or potentially dangerous. 
Confidentiality in PNG has rarely been the subject of critical examination. Lepani has argued that confidentiality has been raised as an issue in the Trobriands, particularly in terms of the difficulty in achieving it, and its denial of social relationships of care and support (2012:173-174). In this article, I contribute to this literature by exploring how confidentiality is practiced by health workers, yet is becoming the subject of critical reflection in Lihir. I argue that as 'breaking the silence' has come to be seen as key to HIV prevention efforts, confidentiality has come under scrutiny. In this context, other silences have escaped attention.

\section{METHODOLOGY}

In this article, I draw mostly on fieldwork undertaken in two trips to the Lihir Islands in 2011 and 2012. The initial purposes of this work were to explore the extent of HIV, and understandings of the infection in Lihir, to determine what HIV preventative efforts had been introduced and the extent to which health staff believed that these were working, and what staff thought could be done better. Interviews were conducted with health staff and key stakeholders in health and HIV, including the subdistrict health manager, all aidpost workers, three staff at Palie Health Centre, four staff at the Lihir Medical Centre, key staff in Newcrest Mining, staff from the Lihir Islands Community Health Program, and women's leaders from the two women's associations. I attended a number of meetings of women's groups, an antenatal clinic, and immunization clinic. I wanted to attend any HIV awareness activities, yet none occurred in the eight weeks I was there, none had occurred in the weeks prior to my fieldwork, nor were any planned in the weeks following both my departures. Interviews and meetings were not tape recorded, but detailed fieldnotes were taken at the time as a record, and fully written up within 48 hours. Statistics were also collected from aidposts and health centers. Interviews were analyzed and coded for key themes, and to discover who raised these various themes.

The material gathered in these two recent visits is supplemented by my longer-term understandings of the context of Lihir. I conducted doctoral fieldwork on the outer island of the Lihir group, Mahur, during 1997-1998, focusing on emotions and personhood. I was then employed by Lihir Management Company (LMC) from 2000-2002, working as a researcher on community health, women's development, and other issues. These three years, and visits in 2003 and 2004, provide deep background knowledge of the islands.

\section{THE LIHIR CONTEXT}

Lihir is a group of four islands located to the northeast of the New Ireland mainland in Papua New Guinea, and comprises a large island, Niolam, and three smaller outer islands of Malie, Masahet, and Mahur. The first case of HIV in Lihir was detected in 2002, and since then further cases have been detected and confirmed to make a total of about 95 cases as of 2014. Voluntary counseling and testing (VCT) has been officially available on Lihir since 2011, although testing was offered at the Lihir Medical Centre for employment medicals and on request, as well as offered for all pregnant women, from at least 2000. Each employee of the mining company has a pre-employment medical and an annual medical, and HIV testing is offered as part of this process. Antiretroviral therapy (ART) has been available in Lihir since 2011, and 15 people were being 
treated with ART in May 2014. For adults, the majority of confirmed positive cases by 2011 were in men (62\%), with an average age of 36 years. Women who tested positive tended to be younger (30 years on average). On the data that are available, the majority of cases of HIV appear to be through heterosexual transmission, although there are a small number of mother-to-child cases of transmission (four by mid-2011). Health workers suggested that the true number of people infected with HIV in Lihir was likely to be much higher than those confirmed, and that many people refused pre-employment or annual HIV tests as part of their medical check-up.

Niolam is the site of a large gold mine, which began construction in 1995 and production in 1997, and since 2011, has been operated by Newcrest Mining. ${ }^{1}$ Mining is predicted to continue until 2031, with production from stockpiles continuing until about 2044. The Lihir group is home to about 15,000 Lihirians, plus 4000 informal migrants and at least 4000 formal migrants who are employees of the mine or its contractor companies. Most of these are employed on a flyin-fly-out basis from their home provinces around Papua New Guinea. A large proportion of informal migrants come from nearby islands and areas in New Ireland, but also from all over PNG, including Highlands Provinces.

While many Lihirians now have wage employment, and some have access to money through business interests, compensation, or royalties, the majority of people are still heavily dependent upon subsistence agriculture. With the advent of mining there has been the construction of a ring road around Niolam, and a small township called Londolovit has been built just north of the mine. The town contains supermarkets and small stores, banks, a hospital, and a residential area, with camps full of dormitories for fly-in-fly-out employees, a section for employees of the Provincial and National Governments, and the 'townsite' for employees of the mine who reside permanently on site.

Lihir has been classified as a High Risk Setting by the PNG National AIDS Council (NHASP 2006:11) for two reasons associated with mining: the high levels of both formal and informal migration, and the relatively high levels of income in the PNG context. Despite this classification, as I examine next, efforts for prevention have been somewhat slow or muted.

\section{SILENCES IN HIV PREVENTION IN LIHIR}

\section{Early Approaches to HIV}

When I was first in Lihir in the late 1990s for my doctoral fieldwork, no one was known to be infected, and HIV was seen as a potential threat yet to appear from outside of the island group. People were somewhat concerned about the virus, and while they wanted to know more, there was almost no informal discussion about it. At the Catholic Family Life course conducted in 1998 on Mahur Island, it was briefly covered in the context of building relationships, and at my farewell party, some of the young men performed a skit about HIV as a virus that renders white blood cells unable to protect the body. This skit did not make clear how HIV was transmitted, but focused instead on the impact of HIV on the body and how it would eventually cause death.

In 2000, as a member of the Community Relations team of the mining company, I helped to organize and I attended a World AIDS Day event, which consisted of a group of us touring the township on the back of a flatbed truck dressed in World AIDS Day T-shirts, with posters and condoms. Later there was a skit about HIV performed at the market, which made it clear that 
HIV could be caught through sexual relations, particularly by having sex with a woman at the 'marketplace,' a euphemism for sex work. World AIDS Day that year was jointly organized by the Lihir Red Cross, the Lihir Medical Centre and the mining company. Each year since then, there have been efforts to promote awareness about HIV particularly on World AIDS Day.

In the late 1990s and early 2000s, efforts of the mining company to prevent HIV were very low key. At the compulsory induction sessions, little information was provided. At the one I attended in 2000, the instructor stated only that "things were going around" on the island group, "you know what I mean." This was the extent of education on HIV and its prevention. The mining company was also reluctant to be associated with more proactive efforts to promote condoms. In 2001, in a report on health for the mining company, I recommended that condoms be made freely available through vending machines in the mining camps. At that stage, condoms could be purchased from a couple of stores, and were available for free from the Lihir Medical Centre upon asking for them. There were also boxes of condoms unopened at Palie Health Centre, which is run by the Catholic Church: center staff refused to distribute them or make them available. The staff at the mining company were concerned that making condoms available in camps would suggest that they condoned casual sex, and so they were unwilling to install vending machines. They argued that access via stores and the hospital was adequate, especially given that there were no recorded cases of HIV in Lihir, despite testing being available for pregnant women and mining workers. Yet people with whom I spoke at the time noted that access was difficult, as men seeking condoms might be related to nurses or store workers who were generally female, and shame meant that they were unlikely to ask for or purchase them. These early prevention efforts seemed ad hoc and isolated. The prevailing sense at the time was that sexual matters were not something that should be talked about publicly.

There was little discussion about sexual matters while I resided in the village, other than in terms of who might be having illicit relations with who, and occasional bawdy jokes. Women with whom I spoke stated that they had been told little about sex or pregnancy by their parents or in formal settings such as school. There certainly was no open discussion about sexual acts, feelings, problems, or illnesses. It is difficult to know whether this was always the case or whether Christianity made this less acceptable. Lihirian culture has rules against opposite sex siblings explicitly speaking about sexual matters with each other or in the presence of the other. Overlaying this are Christian values that locate sexual contact as acceptable and safe only within the context of marriage (Hemer 2013). These factors made HIV education difficult, as health workers had begun to acknowledge.

\section{Recent Approaches and Authoritative Critiques of Cultural Silences}

In the past decade, HIV has become a significant issue in Lihir, and prevention efforts have changed considerably. There have been improvements in access to VCT, medication, condoms, and health education. A more explicit critique of cultural silences has developed particularly among health workers and residents or workers who provide HIV prevention education. They note that while the situation for HIV prevention has improved, Lihirian culture continues to make discussions of sexuality difficult. A key member of the Lihirian landowners' association stated that "culture prevents open dialogue on this subject," and that shame was a key issue in tackling HIV.

A key group for HIV education from 2009 was the Tutorme Women's Association. It brought in the Kabongklakal Theatre Group from Madang to Lihir to perform both in the villages and in 
town near the market. Tutorme worked with the performance group to tailor HIV performances, typically done by the group, to fit the Lihirian context. Women who led Tutorme said that the education was "a slap in the face" for people in the village because it was more open than they were used to. Like many others, they said that Lihirian culture promotes silence around HIV.

Most of the health HIV education in Lihir follows the ABC model of Abstinence, Be faithful and wear a Condom, as promoted in Papua New Guinea more generally (Dundon 2009). This was the model endorsed through the early skits on HIV, and by most health workers. Although staff at Palie Health Centre and some of the aidposts restricted it to the first two-abstinence and be faithful (cf. Indistange and Movono 2004 cited by Dundon 2009:174). There was no mention of the broader ABCDE model of prevention, which includes 'Do something else other than penetrative sex' and Educate (Benton 2008:321; see also Hammar 2010:37-38 for alternative versions). The key discussions around HIV in Lihir linked its spread to a moral discourse about people's inability to follow the dictates of this $\mathrm{ABC}$ model, particularly in terms of sexual relationships outside of the context of marriage (Eves 2003).

Critical of this limiting approach to HIV education was Jimmy Peter, who worked for the mining company, volunteered with the Red Cross, and coordinated a performance group known

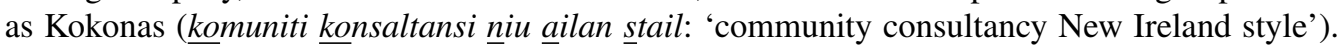
The company had allowed him, in his role within community relations, to provide HIV education when groups from the company went out to villages for consultancy and education. In these cases, HIV education was often part of a program that covered other issues, such as road safety, mining benefits, employment opportunities, and other health issues. Jimmy also has provided HIV education to groups within the workplace when they ask for it, and through the Kokonas performance group had provided education at the Namantanai Mask Festival and at key sporting events in Lihir.

Unlike most education on HIV in Lihir, in his work Jimmy went well beyond the ABC model, and argued that people need to speak openly and that there is little opportunity for many to access knowledge about sexuality and gender relations. He said that while men talk amongst themselves about sex, girls speak and are taught very little in this area. He also contended that while performances are highly worthwhile, they need to be contextualized and followed by open discussion and question time. Hence Jimmy has raised issues such as negotiating safe sex, rape in marriage, phone sex, and pleasure in a range of sexual actions that can be safe even without a condom. He demonstrated how to use condoms, and how to recognize signs of sexual infections. He aimed to keep his discussions neutral and not moral. Responses to his education have ranged from anger in the early years, to shame, particularly from young women; yet more recently people have come to thank him afterward for his candor. Jimmy considered it crucial for HIV prevention to break through silences or shame about sexuality. In this he, and other key educators and health workers in Lihir, has followed the authoritative discourse on HIV prevention: that 'breaking the silence' is key to preventing HIV. Yet this discourse highlights particular silences as problematic and obscures others.

\section{Invisible Silences in HIV Prevention}

Condom access has improved in the past decade, yet is still patchy. At the Lihir Medical Centre there is no longer any need to personally ask health workers for condoms, as they are freely available in boxes and vending chutes. Five of the seven aidposts now willingly give out condoms, 
although only one made them available without people having to ask for them. One aidpost worker said that she was willing to give them out but no one is interested or asks for them. Health workers at the aidpost and subhealth center where condoms are not readily available stated that this is because it is against the teachings of the church. Palie Health Centre still does not make condoms available despite boxes of them present in the Centre. Health workers, including one trained in VCT, stated that people in the village do not know how to use them. The mining company still did not have vending machines in camps as of 2012. Despite this, there is little critique of condom availability or lack of health education on their use. This gap in HIV prevention, principally based on moral or Christian discourse, largely escapes comment.

Condom access clearly needs to be paired with education on how to effectively use them and other methods of prevention. In mid-2011, there was visual educational material such as posters available at aidposts and health centers. Most had some health education and prevention posters on their walls, including on tuberculosis, diabetes, cholera, and immunization, yet few specifically on HIV. In the two VCT rooms for HIV, at the Lihir Medical Centre and at Palie, there were posters on HIV, many in English and some in Tok Pisin (Pidgin English: the lingua franca in PNG). Yet these posters were only accessible to those already seeking counseling or testing. Within the Subdistrict Government office there were some posters about HIV: one in English saying "Stay true for life" and asking "Do you know who you are sleeping with?" Another was aimed at men in Tok Pisin, stating that men should not fight with women (noken birua long ol meri), that arguments weaken families and make them vulnerable to HIV. One aidpost had instructions for the use of the female condom, in English. Another aidpost had a poster, also in English, stating that mothers who are HIV positive can still breastfeed. Another had a poster of a Papua New Guinean man, with a condom, saying Mi no poret, mi gat banis ("I am not afraid, I have prevention"). No posters that depicted how HIV is transmitted, what impact it has on people, or practical instructions on how it may be prevented.

The posters on HIV available in Lihir are produced nationally and distributed through health networks. These have been the subject of critical discussion by anthropologists in terms of their content and how they are understood by rural Papua New Guineans (see, for example, Hammar 2010; Lepani 2012; McPherson 2008). In Lihir, there was no critical discourse by health workers or key educators such as the women's groups about the content, pictures, or language of HIV prevention posters, nor their availability and positioning.

The HIV prevention posters can be contrasted to those for cholera, about which there were posters at almost all aidposts, in Tok Pisin, that gave key words and descriptions on how to prevent cholera, and detailed instructions on what it was and what to do if someone thought that they had been infected. These posters for cholera were paired with an education campaign organized by the mining company, Newcrest, and the Lihir Medical Centre, which systematically toured all villages as well as workplaces following one case detected in a fly-in-fly-out employee in 2011.

While there have been efforts to provide interactive outreach programs on HIV to Lihirians and workers, these have not had the attention or systematic nature of the efforts against cholera. For the workforce, material has been incorporated into inductions, but it is still very short and low key. The mining company and Lihir Medical Centre have generally been at the forefront of education on HIV annually for World AIDS Day since those early efforts in 2000, and in 2012 organized a person living with HIV to provide education sessions to the mining workforce. In 2013 Newcrest hosted BAHA (the PNG Business Coalition against HIV/AIDS) to provide four days of training for business representatives on the island group, particularly aiming to provide understanding 
of HIV workplace policy (The National 2013). They also certified one Newcrest employee as a recognized trainer. It appears that the workplace in Lihir has become a central site for HIV education for employees, both Lihirian and formal migrants.

For the remaining population of Lihir, HIV education has tended to come through health personnel. During 2012 the person appointed to the Lihir Medical Centre to concentrate on HIV also oversaw the tuberculosis program. He was on a 15-day-on, 13-off roster, meaning that for nearly half of the time he was not on the island. It was his task to counsel and test for HIV, maintain the database on HIV cases, manage those with HIV and ART access, and oversee the treatment of those with AIDS. Given this, he had little time to go out of the Medical Centre to villages located up an hour or more away to provide education. Only a few health workers at aidposts stated that they continued to provide health education about HIV on a one-to-one basis and to village groups, but this appeared to be sporadic. However, there also appeared to be a gradual shift toward more accessibility of education about HIV and methods of prevention such as condoms and access to VCT and ART. Most health workers at aidposts felt that Lihirians had a good understanding of HIV and how to prevent it, and issues of prevention were more about people not following the advice rather than not understanding it. The key issue raised in HIV prevention was therefore about cultural silences or shame around sex, not about the availability of condoms, posters, and health education that are impacted by institutional decisions and national policy (see Hammar 2010; McPherson 2008; Wardlow 2008). The other issue raised was about confidentiality, and the role this might play in undermining people's understandings and awareness of the seriousness of HIV in Lihir. It is to this that I now turn.

\section{HIV AND CONFIDENTIALITY IN LIHIR}

On the surface, practices of confidentiality in Lihir are a success in that there seemed to be little knowledge or speculation about who actually has HIV, and no apparent discrimination or violence toward people living with HIV/AIDS. Instead of HIV being associated with particular individuals, there was a diffuse sense of threat about the virus. Many Lihirians seemed aware of the approximate number of cases on the island, and that both Lihirians and migrants were infected. Many more assumed that mostly migrants were infected, and this was associated both with a sense of some safety in Lihirian villages and with mild anger or fear toward migrants.

In 2012, the Lihir Medical Centre and Palie Health Centre provided confidential counseling and testing for HIV, and two key health workers were trained to provide this. Both staff were well versed in practices of and regulations about maintaining confidentiality in Papua New Guinea. They maintained strict procedures for confidentiality, such as keeping their records carefully maintained and private, and not disclosing people's HIV status to anyone, including their family. Given that these staff treated other illnesses, people visiting them were not automatically associated with HIV, which assisted in maintaining confidentiality. For patients undergoing treatment with ART or for illnesses associated with AIDS, even at ward rounds there was an effort to maintain confidentiality so that staff referred to HIV-positive patients as having a 'retroviral illness' or even 'High 5.' In terms of information sharing among health workers in Lihir, the general statistics of the number of cases of HIV are known, but little else is.

While I was in Lihir in 2011, a particular case was troubling the health workers specializing in HIV. A young mother had been diagnosed as positive during pregnancy. Given that at the time 
no one in Lihir was authorized to offer ART or VCT, there was no medicine to prevent vertical transmission to the baby, and it tested HIV positive when it was some months old. ${ }^{2}$ The health workers understood that the mother was likely to have got HIV from her first husband, who had affairs and who eventually abandoned her. The woman was counseled to tell her current husband about her HIV status, but she had not. Health workers had chosen to respect confidentiality and not disclose her HIV status to her husband, despite that under the HAMP Act they had the right to do so given that she had been counseled, had refused, and so was putting someone else at risk (Government of PNG 2003:14). It was not clear that the health workers knew of the provisions to break confidentiality in circumstances such as these. The health workers stated that they were waiting for the baby to become ill, and then they would introduce the possibility of HIV to the husband and counsel him to get tested. This seemed the least disruptive way of handling the situation.

Through this case, it became apparent that there was little sharing of information between health workers. The woman described lived on one of the outer three islands of the Lihir group, and yet all health workers on the outer islands said that they had no cases of HIV on their islands, assuming that all cases were on the largest island of the group, Niolam. Under the HAMP Act, a health worker has the right to disclose statistical information about HIV cases (Government of PNG 2003:13) to assist other health workers in providing targeted HIV education. One health worker commented that if there were any cases on her particular island, then people living in the villages would be more aware and more careful with their behavior. Particular understandings of the maintenance of confidentiality seemed to be blunting people's sense of threat from HIV, and making prevention less important and more difficult.

\section{CRITICAL VIEWS ON CONFIDENTIALITY}

Despite the stance mentioned previously that promotes and values confidentiality, a number of people raised confidentiality as contributing towards apathy or a 'don't care' attitude toward HIV in Lihir. Most health workers interviewed, and many other educated Lihirians, suggested that Lihirians in the village understood the nature of HIV well. They said that the health education had been done, and people knew what HIV was, how it could be caught, and how to prevent it. Yet it was suggested that people did not follow advice to prevent HIV, as they were not concerned about it: ol i no busi tumas ("they are not concerned about it"), ol $i$ no care ("they don't care"), ol $i$ no wari tumas ("they aren't too worried about it"). This lack of concern tended to be read from behaviors such as women getting pregnant before marriage, and broken marriages, which locals often associated with men's employment. A number of people explicitly commented on the gap between knowledge and behavior. In this context, as noted also, the behavior that appeared to be expected was particularly the A and $\mathrm{B}$ of the $\mathrm{ABC}$ model—abstinence and be faithful-less often the $\mathrm{C}$ for condom use.

When the gap between knowledge and behavior was explicitly explained, it generally related to the lack of deep understanding of the implications of HIV infection. One health worker commented that people needed to have a case in the village to luksave (understand) what it really means. A number of health workers and Lihirian women's leaders noted that confidentiality was the key problem in people struggling to take HIV seriously. Some argued that if people's HIV status were known generally, then they would make more effort to protect themselves. Women's 
leaders were concerned about Lihirian women's ability to protect themselves, given that they believed that mining was making extramarital sex more common, and that the use of condoms in marriage was largely unacceptable. Their comments raised gender relations in Lihir as an issue in HIV prevention; yet women saw protection as arising from challenging confidentiality rather than a change in gender relations.

Other people argued that if a person's HIV status were known by a select group of health workers, then health education in the village where the person resided could be targeted to ensure treatment and follow up of the person infected, and it would assist in contact tracing for testing of other people. Confidentiality was seen to make it much more possible that infected individuals would either spread the infection or not get appropriate treatment. A number of people openly stated that it was quite possible that a person infected with HIV would behave badly and purposely spread HIV; this was 'PNG style' behavior. Here, the person with HIV is seen as a potential willful threat to the safety of others.

Finally, one health worker discussed the difficulties of confidentiality in a context of high migration. Many of the cases on Lihir are lost to follow up when they move away from the island group. This health worker was concerned about whether people would continue to get their CD4 counts checked - a service available through the Lihir Medical Centre-so that they would start on ART when needed, or whether they would surface at some stage later in another part of PNG with AIDS-related illnesses. He was sure that some people diagnosed positive in Lihir had already been counseled and tested elsewhere, and that unnecessary resources were being wasted on repeated antibody testing as people moved around the country (Hammar 2010:107).

In most cases, confidentiality per se was not the problem, but in particular cases when dealing with HIV it was applied too rigorously. One health worker suggested that HIV needed to be treated like other illnesses and spoken about more openly, particularly within the confines of the Medical Centre and in the context of the treatment of AIDS. In the cases mentioned previously, arguments were being made to relax certain practices of confidentiality to allow for better tracking, care, and testing. Confidentiality, while upheld and highly valued in the health care context in Lihir, in these cases was seen as a form of silencing, which undermined the ability of health workers to appropriately prevent and treat HIV.

\section{SECRECY, SILENCE, SEXUAL RELATIONSHIPS, AND ILLNESS}

What were the "cultural values" (cf. Butt 2011) around confidentiality and silence? In Lihir, there is a high value placed on talking, speech, and revelation, as well as on concealment and discretion. Speech in the daytime was categorized into general talking (tetnge), which may be brief greetings, sharing of information, discussion, and explanation (known as toksave in Tok Pisin). There could also be joking (eretek), and more negative forms of gossip (tetnge piel) and argument (eremsu). Talking at night was known as panpan, which conveys a sense of shared convivial space and conversation. Oratory was not a highly developed art, but all feasts were the scene for discussion within the men's house.

Yet concealment was also an aspect of managing knowledge and relationships. Concealment was sometimes institutionalized, as with certain forms of ritual or magical knowledge. Magic for gardens, for growing pigs, and for shark catching is held by particular individuals. It can be passed on, but generally this requires a close relationship and some form of payment. Other 
forms of ritual or magical knowledge can be passed on through processes of initiation and gradual learning, such as is the case for Pindik, Tena Buai, and Iniat (forms of magical knowledge and secret associations, see Eves 1995, 2004; Hemer 2013; Wagner 1986). It is commonly known that this knowledge exists, but its content is unknown. The knowledge of health workers who test for HIV and treat AIDS is understood as a form of concealment-people know that they have knowledge that is not appropriate for them to share.

In other cases, concealment of knowledge in Lihir is not institutionalized. Instead there is discretion on certain topics, particularly between certain people. As mentioned, cross-sex siblings cannot discuss sexual matters in the presence of one another. Also, menstrual blood or blood shed during birth generally is not discussed in the presence of men, particularly brothers or male children. This discretion is also the key 'silence' on HIV, and that has become the focus of authoritative critique.

In some cases, therefore, the revelation of knowledge is either forbidden or managed discretely; in other cases things are entirely unknown. Generally in Lihir intimate relationships begin in secret-they are entirely concealed, particularly if the parties are young or if it is a relationship outside of marriage. The two people concerned often decline to speak of this to anyone, and conceal signs of their meeting. The first sign of a relationship is often pregnancy, which prompts others to begin to speculate on the paternity of the child. Hence something that is completely unknown becomes known, yet still concealed, sometimes for years.

While talking is valued, therefore, concealment is also valued, and knowing what can be said, to whom and when, is a marker of social intelligence. As Foucault states, "what one says and what one does not say" are not in a binary relationship (1990:27). Instead the relationship is complex and multilayered. Simmel considers this as the "play" of two interests, concealment and revelation (1906:466). He notes that despite not speaking or aiming to conceal information, generally people betray themselves, and at least the existence of a secret becomes known (456). Through this, it is possible to see the relationship between secrecy and silence, where a person can be silent on a particular topic, at particular times, and with particular people, and hence 'keep' a secret even if the fact of the secret is known. Gell, in correspondence on secrecy and meaning in ritual in Melanesia, commented that "what is most important is not what is secret, but that it is secret" (Gell 1980:737).

In Lihir, too, a person can be silent where there is no secret. These silences in social relationships were almost always cast as meaningful. While talking for no reason was viewed with disdain, and known as maus wara (verbal diarrhea), not speaking at all marked either a deliberate or uncontrolled inability to engage in social relations. Mus was a form of sulking directed at the person who had caused anger, and was a withdrawal from social relations marked by silences and the refusal to share food and space. In this case the silence was only directed at the person who caused the anger, while social relations with others continued as normal.

Other than mus, a person who was deeply worried or grieved was understood often not to be able to speak. This could be across all social relationships rather than directed at a single person. This was viewed by Lihirians as of grave concern, and efforts were always made to re-engage the person through banter, light conversation, and the distraction of stories.

Serious illnesses were often marked by silences and the withdrawal of a person from all social relations-the person would refuse food and conversation. As with someone who was seen to be worrying, this was met with efforts to get the person to talk and eat, in addition to seeking either biomedical or traditional medical help. Where this was unsuccessful, family members would 
often then engage members of the community to conduct short church services and prayers with the person. There was generally much quiet discussion among family members and the wider community about what was troubling the person or making them ill: serious illness is known and acknowledged within the community. Talk and engagement in discussion were seen as both a marker of health and a way to return a person to health through distraction and prayers.

Infection with HIV is different to other serious illnesses because it is generally not known about and acknowledged. Rather than being marked by silences in social relationships, HIV is concealed, often completely. Rather than a withdrawal from social relationships, the person continues to engage with others, and their HIV status is completely unknown. This does not allow others to know there is silence, secrecy, or illness, nor allow them to take appropriate care of that person. Most health workers found this to be understandable in terms of confidentiality, yet Lihirians seemed to be uncomfortable with practices of confidentiality that distinguished HIV from the way that they usually manage illness. The confidentiality and reluctance to disclose maintained by health workers and people living with HIV were understood as a form of silence, and hence were met with concern and critique.

Despite these concerns about confidentiality, no health workers suggested that they should break the confidentiality of their patients. They were reluctant to do so even when legally allowed, and were concerned about the possibility of discrimination or even violence between spouses or community members when HIV status disclosed. Instead there seemed to be a desire that HIV infection could be more like other illnesses such as tuberculosis, where no one was particularly concerned about silencing, confidentiality, or discrimination.

\section{CONCLUSION}

People living and working in Lihir are quietly debating how best to prevent and manage HIV in their particular cultural, social, and religious context. Issues around concealment and revelation, breaking the silence and upholding confidentiality, have become key areas of debate. Following authoritative discourse on HIV prevention, open discussion has come to be seen as crucial, and cultural silences around matters of sexuality have been heavily critiqued by health workers as obstacles to effective prevention. This is the "discourse that is authorized" (Foucault 1990:27).

Questioning the virtues of confidentiality is also part of that debate. The literature on confidentiality and prevention of HIV suggests that HIV can be prevented where people have good knowledge of transmission and the ability to act to negotiate safe sexual practices. Confidentiality is seen as crucial to the prevention of discrimination and stigma against those who are HIV positive. It is constructed as an essential and positive form of secrecy that upholds human rights. In these terms, prevention should not rely on knowing who has HIV.

Yet in Lihir, while confidentiality is upheld by health workers and is seen as critical for the prevention of discrimination, some educators on HIV link it to the apathy that appears to characterize responses to HIV prevention in the islands. It is said to undermine the ability to trace those who have HIV, to get people to accept testing, and to prevent those who are positive from infecting others. It is also said to undermine effective communication between health workers both within the islands and at the National level. Confidentiality is not viewed by some as desirable, but rather, as a form of effective silencing that contributes to the difficulty in preventing and treating HIV. 
In the context of these two silences-the culture of silence around sexuality and confidentiality - other silences go unnoticed or at least are not the subject of open authorized critique. These are the things that "one declines to say, or is forbidden to name" (Foucault 1990:27). Hammar (2010) has noted the pervasive silence on issues of gender relations in Papua New Guinea with respect to the spread of HIV, or the use of risk groups that obscure the danger for women in marriage; this equally applies to Lihir. Like other anthropologists (e.g., Wardlow 2008), I have also noted the practices that make condoms difficult to access even through mainstream health services, although this does not figure as part of the critical discussions about HIV prevention. The institutional forms of gender relations, and the moral and Christian discourse that underpins health provision and education, are rarely spoken or named.

As the numbers of HIV cases continue to rise in the island group, the pressures around silence, disclosure, and confidentiality are likely also to increase. The challenge will be to balance competing concerns about HIV prevention, management, and treatment, with the need to protect confidentiality and prevent discrimination, perhaps best achieved through a more revelatory dialogue about invisible silences.

\section{ACKNOWLEDGMENTS}

Ethics approval for this research was granted by the University of Adelaide, and separately by the Research Committee of the National AIDS Council of PNG. This article arose out of a discussion article written and presented at the Sexualities, Sexual Rights, and HIV in PNG and the Pacific Workshop Symposium, Canberra Australian National University in 2012. This article was shaped through substantial discussions with Jimmy Matapi Peter who also attended the symposium, and who has done extensive education and research on HIV/AIDS throughout PNG, but particularly in Lihir. I am grateful for information provided and ongoing discussion with him, as well as with Nick Bainton. This article was also presented at the University of Adelaide, and I am grateful for the feedback of colleagues and to the anonymous reviewers.

\section{FUNDING}

Fieldwork for this project was funded through a Faculty Research Active Grant, and a Study Leave Grant from the University of Adelaide. Attendance at the symposium in Canberra was supported by a grant provided by the Indo Pacific Governance Research Centre of the University of Adelaide.

\section{NOTES}

1. Constructed by Davey Kinhill Flour Daniel, from production in 1997 it was managed by Lihir Management Company, a wholly owned subsidiary of Rio Tinto. It was then sold and became Lihir Gold, and more recently in 2010 was bought by Newcrest Mining.

2. It was not until 2011 that Lihir gained accreditation to officially offer VCT and ART following two health staff completing courses with the PNG National AIDS Council Secretariat. Before that time there was no access to ART or medicine for PMTCT. 


\section{REFERENCES}

Angotti, N.

2012 Testing differences: The implementation of Western HIV testing norms in sub-Saharan Africa. Culture, Health $\&$ Sexuality 14(4):365-378.

Beadle-Holder, $\mathrm{M}$.

2011 Black churches creating safe spaces to combat silence and stigma related to AIDS. Journal of African American Studies 15:248-267.

Benton, K. W.

2008 Saints and sinners: Training Papua New Guinean (PNG) Christian clergy to respond to HIV and AIDS using a model of care. Journal of Religion and Health 47:314-325.

Bond, V. A.

2010 "It is not an easy decision on HIV, especially in Zambia": Opting for silence, limited disclosure and implicit understanding to retain a wider identity. AIDS Care 22(Suppl. 1):6-13.

Burchardt, $\mathrm{M}$.

2013 'Transparent sexualities': Sexual openness, HIV disclosure and the governmentality of sexuality in South Africa. Culture, Health and Sexuality 15(Suppl. 4):S495-S508.

Butt, L.

2008 Silence speaks volumes: Elite responses to AIDS in Highlands Papua. In Making Sense of AIDS: Culture, Sexuality, and Power in Melanesia. L. Butt and R. Eves, eds. Pp. 116-132. Honolulu: University of Hawaii Press.

2011 Can you keep a secret? Pretences of confidentiality in HIV/AIDS counseling and treatment in Eastern Indonesia. Medical Anthropology 30(3):319-338.

Davis, M. and L. Manderson, eds.

2014 Disclosure in Health and Illness. London \& New York: Routledge.

Dundon, A.

2009 Sexuality, morality and lifestyle: The ABC of HIV prevention strategies in Rural Papua New Guinea. The Asia Pacific Journal of Anthropology 10(3):171-185.

Eves, R.

1995 Shamanism, sorcery and cannibalism: The incorporation of power in the magical cult of Buai. Oceania 65:212-233

2003 AIDS and apocalypticism: Interpretations of the epidemic from Papua New Guinea. Culture, Health and Sexuality 5(3):249-264.

2004 The play of powers made visible: Magic and dance in New Ireland. Ethnos 69(3):341-362.

Fielden, S. J., G. E. Chapman, and S. Cadell

2011 Managing stigma in adolescent HIV: Silence, secrets and sanctioned spaces. Culture, Health \& Sexuality 13(3):267-281.

Foucault, M.

1990 The History of Sexuality. New York: Vintage.

Gell, A.

1980 Correspondence: Order or disorder in Melanesian religions? Man 15(4):735-737.

Government of PNG

2003 HIV/AIDS Management and Prevention Act 2003. Port Moresby: Independent State of Papua New Guinea.

Hammar, L. J.

2010 Sin, Sex and Stigma: A Pacific Response to HIV and AIDS. Herefordshire, UK: Sean Kingston Publishing. Hardon, A. and D. Posel

2012 Secrecy as embodied practice: Beyond the confessional imperative. Culture, Health and Sexuality 14(Suppl. 1):S1-S13.

Hardon, A., E. Vernooij, G. Bongololo-Mbera, P. Cherutich, A. Desclaux, D. Kyaddondo, O. Ky-Zerbo, M. Neumann, R. Wanyenze, and C. Obermeyer 
2012 Women's views on consent, counseling and confidentiality in PMTCT: A mixed-methods study in four African countries. BMC Public Health 12(26):1-15.

Hemer, S. R.

2013 Tracing the Melanesian Person: Person and Relations in Lihir. Adelaide, SA: University of Adelaide Press.

Kimani-Murange, E. W., L. Manderson, S. A. Norris, and K. Kahn

2013 "It's my secret": Barriers to paediatric HIV treatment in a poor rural South African setting. AIDS Care 25(6):744-747.

Lepani, K.

2012 Islands of Love, Islands of Risk: Culture and HIV in the Trobriands. Nashville, TN: Vanderbilt University Press.

McPherson, N. M.

2008 SikAIDS: Deconstructing the awareness campaign in rural West New Britain. In Making Sense of AIDS: Culture, Sexuality, and Power in Melanesia. L. Butt and R. Eves, eds. Pp. 224-245. Honolulu: University of Hawaii Press.

Manderson, L.

2014 Telling Points. In Disclosure in Health and Illness. M. Davis and L. Manderson, eds. Pp. 1-15. London \& New York: Routledge

Moyer, E.

2012 Faidha gani? What's the point: HIV and the logics of (non)-disclosure among young activists in Zanzibar. Culture, Health and Sexuality 14(Suppl. 1): S67-S79.

The National

2013 Newcrest employees among staff with HIV knowledge. September 6.

National HIV/AIDS Support Project

2006 High Risk Settings Strategy Report: Moving Beyond Awareness. Port Moresby: National AIDS Council Secretariat.

Nguyen, V.-K.

2005 Uses and pleasures: Sexual modernity, HIV/AIDS, and confessional technologies in a West African Metropolis. In Sex in Development: Science, Sexuality, and Morality in Global Perspective. V. Adams and S. L. Pigg, eds. Pp. 245-267. Durham, NC: Duke University Press.

2013 Counselling against HIV in Africa: A genealogy of confessional technologies. Culture, Health and Sexuality 15(Suppl. 4):S440-S452.

Obermeyer, C. M., P. Baijal, and E. Pegurri

2011 Facilitating HIV disclosure across diverse settings: A review. American Journal of Public Health 101(6):1011-1023.

Obermeyer, C. M., S. Bott, R. Bayer, A. Desclaux, R. Baggaley, and the MATCH study group

2013 HIV testing and care in Burkina Faso, Kenya, Malawi and Uganda: Ethics on the ground. BMC International Health and Human Rights 13 (6):1-14.

Obermeyer, C. M. and M. Osborn

2007 The utilization of testing and counseling for HIV: A review of the social and behavioral evidence. American Journal of Public Health 97(10):1762-1774.

Pigg, S. L.

2005 Globalizing the facts of life. In Sex in Development: Science, Sexuality, and Morality in Global Perspective. V. Adams and S. L. Pigg, eds. Pp. 39-65. Durham, NC: Duke University Press.

Simmel, G.

1906 The sociology of secrecy and of secret societies. American Journal of Sociology 11(4):441-498.

Smith, R. A. and A. J. Neidermyer

2009 Keepers of the secret: Desires to conceal a family member's HIV-positive status in Namibia, Africa. Health Communication 24(5):459-472.

Wagner, R.

1986 Asiwinarong: Ethos, Image and Social Power among the Usen Barok of New Ireland. Princeton, NJ: Princeton University Press.

Wardlow, H.

2008 You have to understand: Some of us are glad AIDS has arrived. In Making Sense of AIDS: Culture, Sexuality, and Power in Melanesia. L. Butt and R. Eves, eds. Pp. 187-205. Honolulu: University of Hawaii Press. 